\title{
DENSIDADE DE BIODIESEL EM FUNÇÃO DA TEMPERATURA: EXPERIMENTAL X PREDIÇÃO
}

\author{
A. M. M. BESSA ${ }^{1}$; F. M. R. MESQUITA ${ }^{1}$; F. R. DO CARMO ${ }^{1}$; H.B.DE SANT'ANA ${ }^{1}$ E \\ R.S.DE SANTIAGO-AGUIAR ${ }^{1}$
}

\author{
${ }^{1}$ Universidade Federal do Ceará, Departamento do Engenharia Química \\ E-mail para contato: alinembessa@gmail.com
}

\begin{abstract}
RESUMO - A densidade é uma propriedade volumétrica relevante para a engenharia de projeto e processos, além de ser utilizada em correlações de outras propriedades, tais como número de cetano e viscosidade. Dados experimentais de densidade foram coletados numa faixa de temperatura de 20 a $70{ }^{\circ} \mathrm{C}$ para os seguintes biodieseis metílicos e etílicos: soja, babaçu, milho e algodão. Três versões do modelo GCVOL foram utilizadas na predição das densidades. Para biodieseis metílicos, os modelos GCVOL-Original e GCVOL-OL-60 apresentaram valores de desvio relativo médio (ARD) inferiores a 0,83\%. A terceira versão estudada (GCVOL-Bio), proposta baseada em dados de ésteres metílicos, apresentou ARD igual a 0,34\%. No entanto, para os biodieseis etílicos os modelos GCVOL-Original e GCVOL-Bio apresentaram desvios maiores que o GCVOL-OL-60 (ARD=0,49\%). Assim, os modelos que representam melhor os dados de densidade para biodiesel metílico e etílico são GCVOL-Bio e GCVOLOL-60, respectivamente.
\end{abstract}

\section{INTRODUÇÃO}

O biodiesel, definido como uma mistura de ésteres alquílicos de ácidos graxos, surgiu como uma alternativa em substituição ao óleo diesel derivado de petróleo por apresentar vantagens quando comparado ao diesel convencional, como redução na emissão de gases de exaustão, excelente lubricidade, alto ponto de fulgor, alto número de cetano, biodegradabilidade e a utilização da biomassa como matéria-prima (Knotheet al., 2008).

O aumento da produção e consumo de biodiesel gerou uma necessidade de estudar de maneira mais detalhada e completa suas propriedades físicas, pois estas são importantes para a base de cálculos de engenharia (Wallek, 2013). Neste contexto, particularmente, ponto de ebulição normal, pressão de vapor, densidade do líquido, eviscosidade dinâmica são as propriedades de grande interesse na simulação de processos. A densidade correlaciona-se com muitas outras propriedades, tais como viscosidade, a tensão superficial, a volatilidade, e a velocidade do som. Assim métodos para predição de densidades são amplamente testados.

Modelos que não necessitam de propriedades críticas são preferíveis em casos onde estes dados sejam escassos (Ihmels e Gmehling et al.,2003). Modelos de contribuição de 
grupos para predição de densidades com aplicação destinada a biodiesel são mais utilizados, pois requerem apenas as estruturas moleculares dos componentes envolvidos para estimar suas propriedades físicas. No presente trabalho, três modelos de contribuição de grupos foram utilizados para estimar densidades de diferentes biodieseis metílicos e etílicos e estes resultados foram comparados com dados experimentais.

\section{METODOLOGIA}

\subsection{Produção do Biodiesel}

Os biodieseis foram produzidos por meio de reações de transesterificação em um reator de vidro com capacidade para $1 \mathrm{~L}$ com quatro entradas superiores nas quais foram acoplados um termômetro e um condensador. As reações de obtenção do biodiesel metílico e etílico de algodão foram realizadas de acordo com as seguintes condições: razão molar óleo/metanol de $1 / 6$ e óleo/etanol de $1 / 9$, catálise alcalina com $1 \% \mathrm{~m} / \mathrm{m}$ de $\mathrm{NaOH}$ e temperatura de $60{ }^{\circ} \mathrm{C}$ mantida constante por um banho termostático. Foram realizadas três lavagens com água e posteriormente aquecimento até uma temperatura de $110{ }^{\circ} \mathrm{C}$ para desumidificação.As composições dos biodieseis puros foram analisadaspor meio de cromatografia gasosa com detector de ionização de chama (FID), com uma coluna capilar de polietilenglicol.

\subsection{Dados de Densidade}

Os dados de densidade foram determinados para os biodieseis metílicos e etílicos de babaçu, milho, soja e algodão em uma faixa de temperatura de 20 a $70{ }^{\circ} \mathrm{C}$, com uma variação de $5^{\circ} \mathrm{C}$. Para isso, foi utilizado um densímetro, modelo DSA 5000 Anton Paar, equipado com uma célula de densidade e uma de velocidade do som, que possuem controlador de temperatura. O equipamento apresenta incertezas nas medições de $1,0 \times 10^{-6} \mathrm{~g} / \mathrm{cm}^{3}$ e $0,1 \mathrm{~m} / \mathrm{s}$, respectivamente para a densidade e velocidade do som.

\subsection{Modelagem Termodinâmica}

Os modelos utilizados para predição de densidades são baseados nos métodos de contribuição de grupos, os quais levam em consideração apenas a estrutura química e a interação entre as moléculas. Elbro et al. (1991)publicou um métodopara a predição de densidades líquidas saturadas, contendo parâmetros para 36 grupos com diferentes pesos moleculares, conhecido como GCVOL-original e representado na Equação 1.

$$
\rho=\frac{\sum_{i} x_{i} M_{w_{i}}}{\sum_{i} x_{i} V_{i}}
$$

Os parâmetros propostos no modelo GCVOL-original representavam uma classe de compostos bastante limitada. Novos parâmetros foram apresentados nos modelos GCVOLBio (Pratas et al.,2011) e GCVOL-OL-60 (Ihmels e Gmehling et al.,2003), os quais possibilitaram a predição de densidades para uma quantidade ampla de componentes. $\mathrm{O}$ equacionamento é o mesmo para os três modelos avaliados, assim a diferença entre eles são os grupos.Os modelos GCVOL-Original, GCVOL-Bio e GCVOL-OL-60 foram utilizados 
para estimar densidades dos biodieseis metílicos e etílicos de babaçu, milho, soja e algodão.A comparação entre os modelos e os dados experimentais foi realizada por meio do cálculo do desvio médio relativo (ARD), como mostrado na Equação 2.

$$
A R D=100 \frac{1}{n} \sum_{n}\left|\frac{V_{\exp , n}-V_{\text {calc }, n}}{V_{\exp , n}}\right|(\%)
$$

\section{RESULTADOS}

\subsection{Composição do Biodiesel}

A composição dos biodieseis metílicos e etílicos, em porcentagem mássica, é mostrada na Tabela 1 .

Tabela 1 - Composição dos biodieseis metílicos e etílicos em $(\% \mathrm{~m} / \mathrm{m})$

\begin{tabular}{cccccc}
\hline & & \multicolumn{3}{c}{ Composição biodiesel metílico (\% m/m) } \\
\hline Ácido graxo & Componente & Babaçu & Milho & Soja & Algodão \\
\hline C8:0 & Metil Octanoato & 6,41 & - & - & - \\
C10:0 & Metil Decanoato & 6,06 & - & - & - \\
C12:0 & Metil Laurato & 46,93 & - & - & - \\
C14:0 & Metil Miristato & 15,82 & - & - & 0,85 \\
C16:0 & Metil Palmitato & 8,07 & 12,75 & 11,36 & 24,08 \\
C18:0 & Metil Estearato & 3,09 & - & 3,60 & 2,13 \\
C18:1 & Metil Oleato & 11,73 & 36,94 & 19,73 & 15,79 \\
C18:2 & Metil Linoleato & 1,89 & 48,70 & 56,93 & 56,08 \\
C18:3 & Metil Linolenato & - & 0,78 & 7,54 & - \\
Outros & Não identificados & - & 0,82 & 0,83 & 1,05 \\
\hline & & & Composição biodiesel etílico (\% m/m) & \\
\hline C8:0 & Metil Octanoato & 3,49 & - & - & - \\
C10:0 & Metil Decanoato & 3,27 & - & - & - \\
C12:0 & Metil Laurato & 46,03 & - & - & - \\
C14:0 & Metil Miristato & 15,22 & - & - & - \\
C16:0 & Metil Palmitato & 8,27 & 12,50 & 11,10 & 28,20 \\
C18:0 & Metil Estearato & 2,06 & - & 4,24 & 2,55 \\
C18:1 & Metil Oleato & 16,17 & 38,52 & 21,42 & 17,83 \\
C18:2 & Metil Linileato & 5,22 & 47,36 & 55,20 & 50,09 \\
C18:3 & Metil Linolenato & - & 0,72 & 7,25 & - \\
Outros & Não identificados & 0,27 & 0,9 & 0,79 & 1,33 \\
\hline
\end{tabular}

\subsection{Dados de Densidade Experimentais e Calculadas}

Os dados de densidade experimentais e calculados pelos modelos GCVOL-Original, GCVOL-Bio e GCVOL-OL-60 são representados nas Figuras 1, 2, 3 e 4 para os biodieseis metílico e etílicos de babaçu, milho, soja e algodão, respectivamente. 

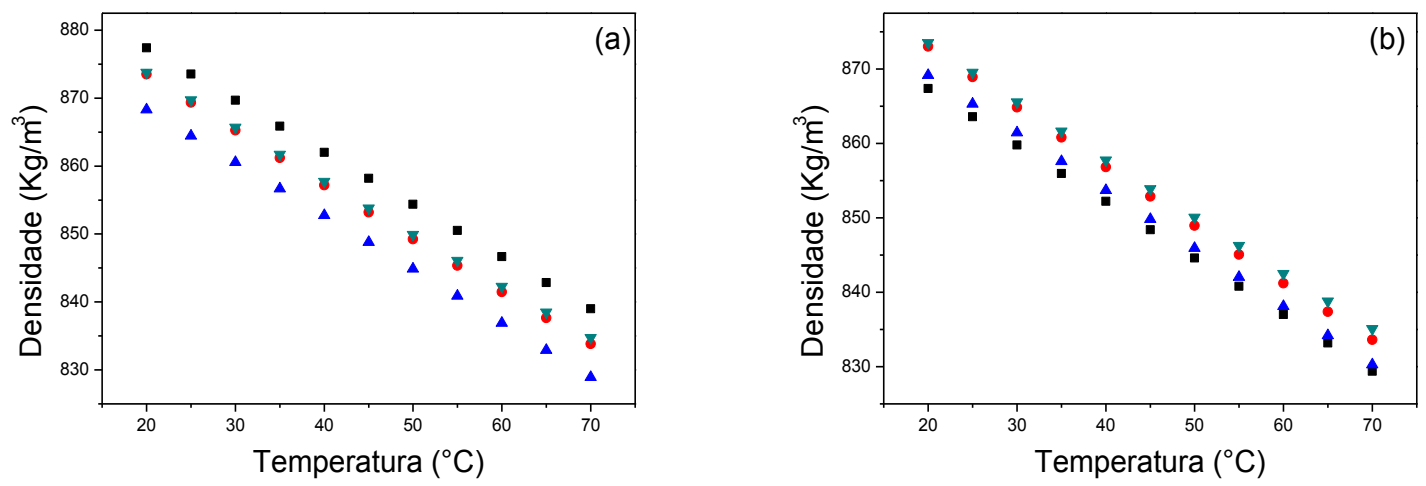

Figura 1 - Dados de densidade para o biodiesel metílico (a) e etílico (b) de babaçu.

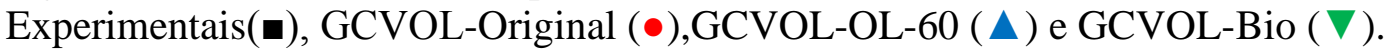
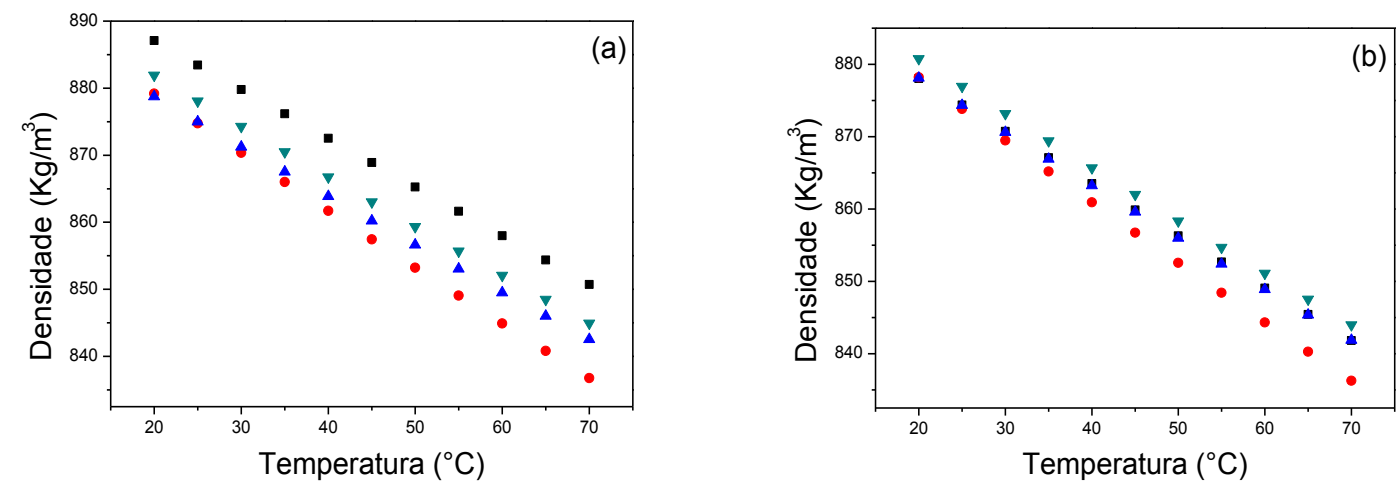

Figura 2 - Dados de densidade para o biodiesel metílico (a) e etílico (b) de milho.

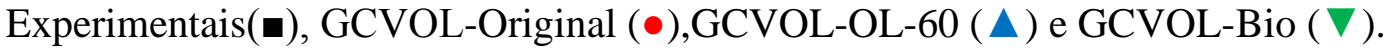
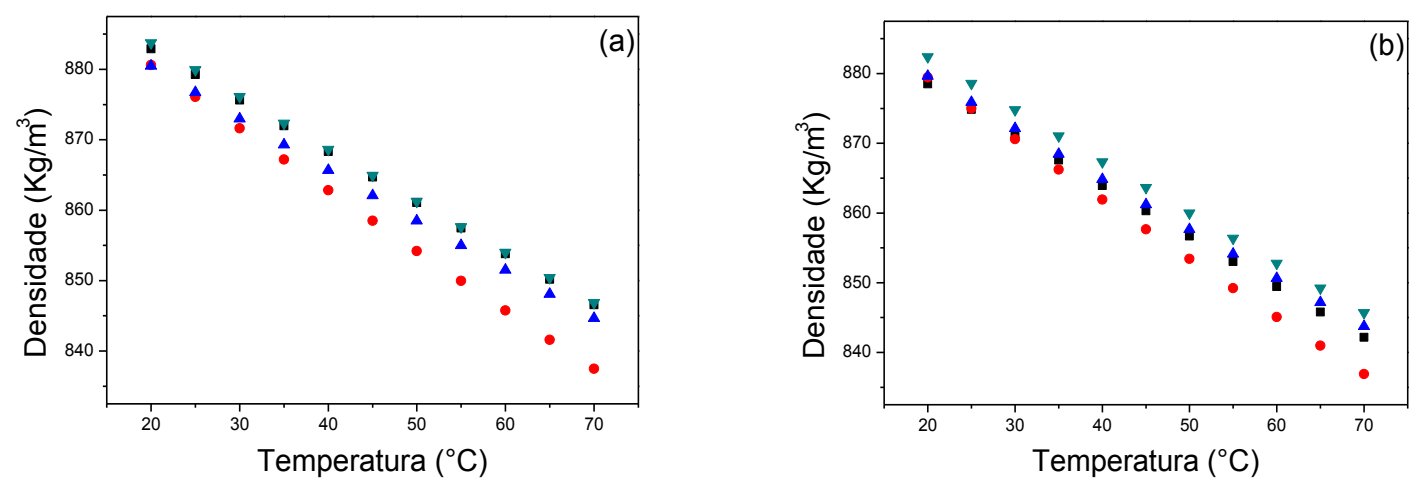

Figura 3 - Dados de densidade para o biodiesel metílico (a) e etílico (b) de soja. Experimentais(•), GCVOL-Original (•),GCVOL-OL-60 ( $\Delta$ ) e GCVOL-Bio ( $\nabla$ ). 

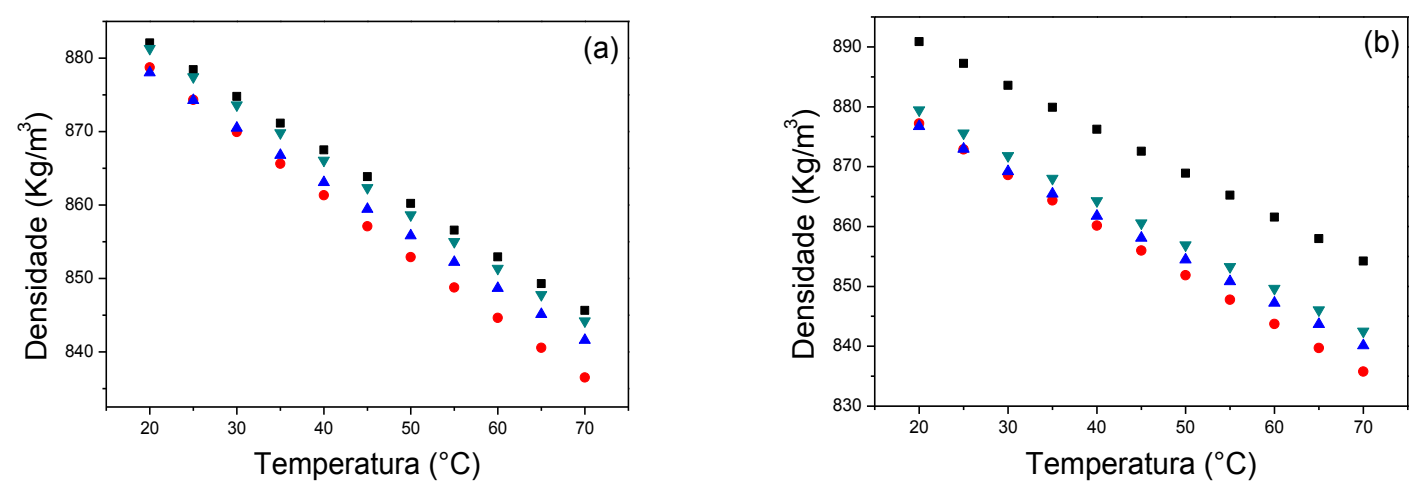

Figura 4 - Dados de densidade para o biodiesel metílico (a) e etílico (b) de algodão.

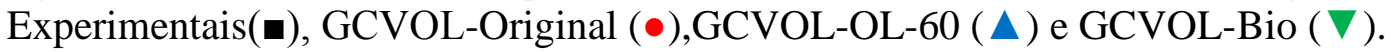

Observa-se nas figuras 1, 2, 3 e 4 que os valores das densidades experimentais apresentam decréscimo linear com o aumento de temperatura, comportamento verificado também para os modelos estudados. Percebe-se que para os biodieseis metílicos o modelo GCVOL-Bio apresentou melhores resultados do que para os biodieseis etílicos, isso ocorre devido a um grupo específico adicionado por esse modelo, que representa melhor as moléculas de ésteres metílicos. Para os biodieseis metílicos de soja e algodão nota-se que os valores de densidade experimentais e calculados pelo GCVOL-Bio são bastante próximos, enquanto para os biodieseis metílicos de babaçu e de milho os valores apresentam maiores diferenças. A composição dos biodieseis metílicos de soja e algodão é semelhante, contendo em sua maioria metil linoleato, em torno de 56\%, já os biodieseis metílicos de babaçu e de milho contem maior concentração de outros metil ésteres, isso indica que a predição de densidades pelo modelo GCVOL-Bio para biodiesel metílico fornece melhores resultados para biodiesel rico em metil linoleato. Os valores de densidades calculados pelo modelo GCVOL-Original mostraram maior proximidade dos valores experimentais para os biodieseis etílicos de babaçu, soja e milho. Para o biodiesel etílico de algodão o modelo mais representativo foi o GCVOL-Bio.

A Tabela 2 mostra os desvios médios relativos obtidos com os modelos analisados para os biodieseis metílicos e etílicos.

Tabela 2 - Desvios médios relativos dos modelos GCVOL-Original, GCVOL-Bio e GCVOL-OL-60, para os biodieseis metílicos e etílicos estudados

\begin{tabular}{cccc}
\hline \multicolumn{4}{c}{ Desvios médios relativos (ARD) } \\
\hline & GCVOL-Original & GCVOL-OL-60 & GCVOL-Bio \\
\hline Biodieseis metílicos & $0,83 \%$ & $0,71 \%$ & $0,34 \%$ \\
Biodieseis etílicos & $0,77 \%$ & $0,49 \%$ & $0,67 \%$ \\
\hline
\end{tabular}

O modelo GCVOL-Bio apresentou o menor ARD para biodieseis metílicos, portanto, o parâmetro proposto por Pratas et al., (2011) torna o modelo mais representativo para dados de densidade quando utilizados na predição de densidade de ésteres metílicos. O ARD obtido pelo modelo GCVOL-OL-60 foi menor para biodieseis etílicos. O modelo GCVOL-Original apresentou os maiores valores de ARD para os biodieseis analisados, no entanto, pode ser 
considerado adequado para o calculo de densidades uma vez que os desvios foram inferiores a $1 \%$.
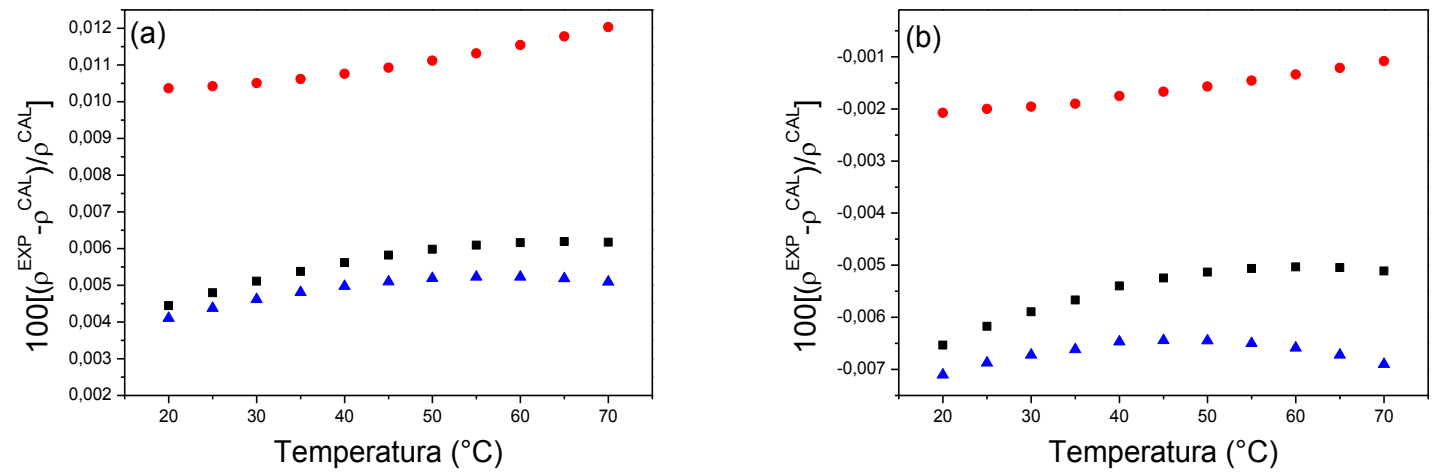

Figura 5 - Dados de desviosrelativos para o biodiesel metílico (a) e etílico (b) de babaçu. GCVOL-Original(•),GCVOL-OL-60 (•),e GCVOL-Bio ( $\Delta$ ).
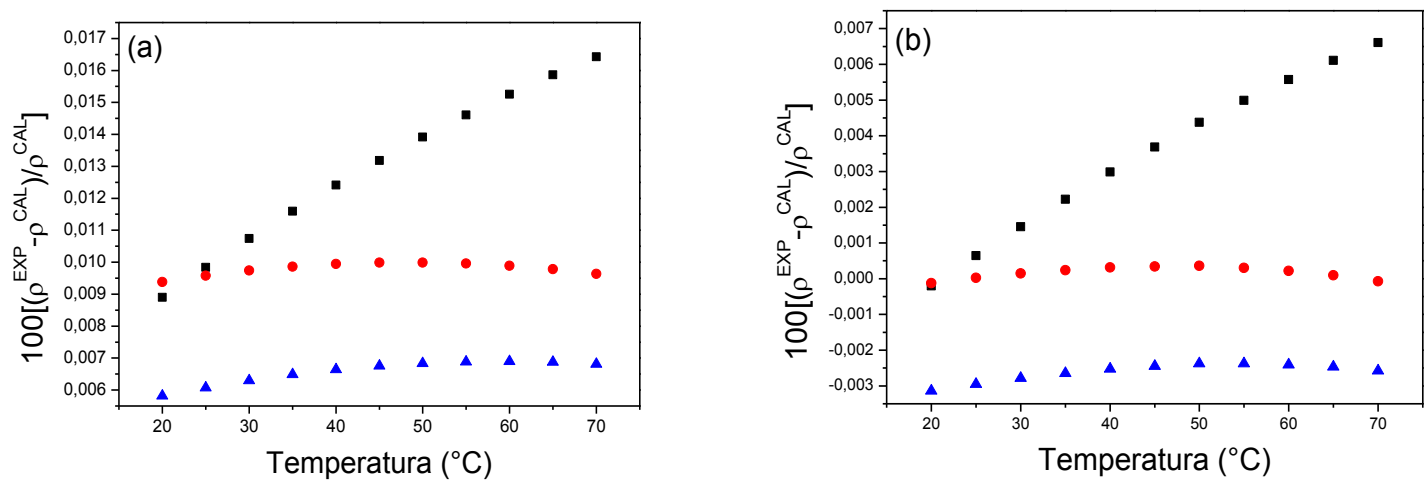

Figura 6 - Dados de desviosrelativos para o biodiesel metílico (a) e etílico (b) de milho. GCVOL-Original(•),GCVOL-OL-60 (•),e GCVOL-Bio ( $\Delta$ ).
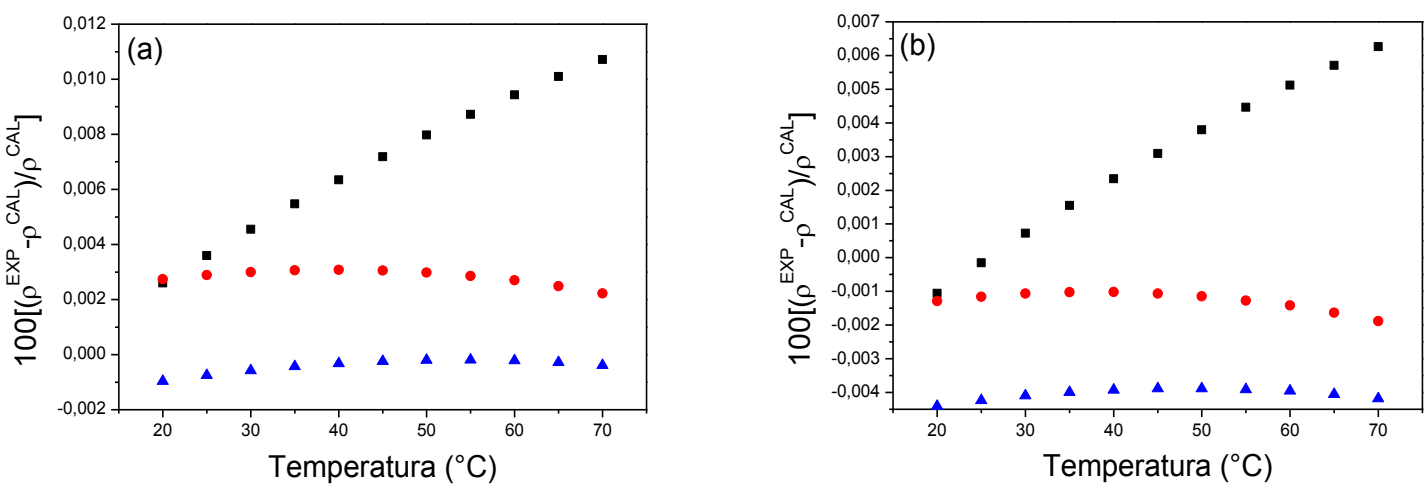

Figura 7 - Dados de desviosrelativos para o biodiesel metílico (a) e etílico (b) de soja. GCVOL-Original(•),GCVOL-OL-60 (•),e GCVOL-Bio ( $\Delta$ ). 

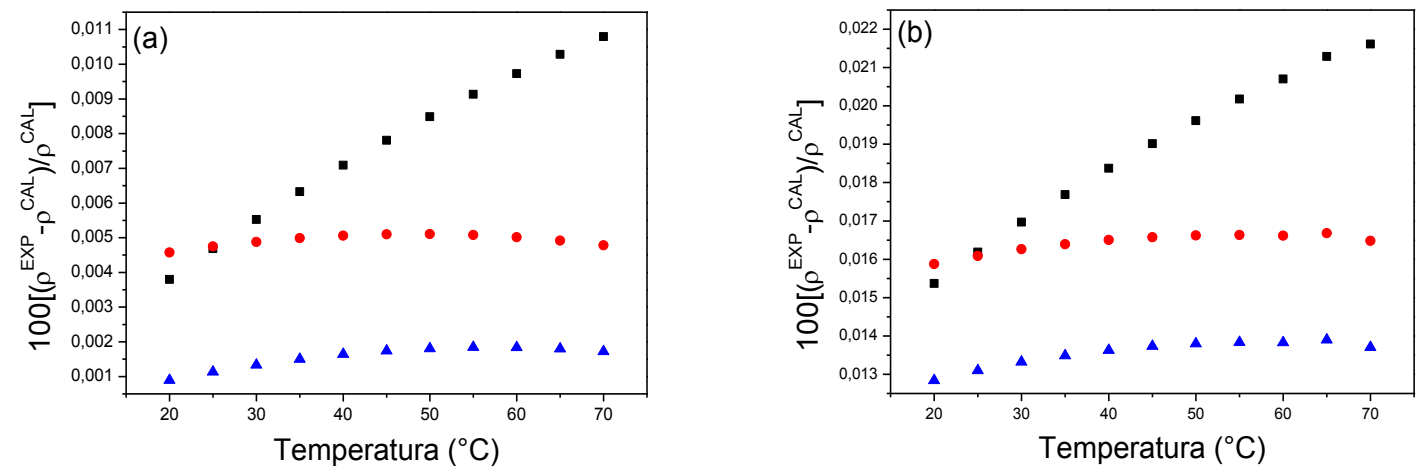

Figura 8 - Dados de desviosrelativos para o biodiesel metílico (a) e etílico (b) de algodão. GCVOL-Original(•),GCVOL-OL-60 (•),e GCVOL-Bio ( $\Delta$ ).

Os desvios relativos obtidos com o modelo GCVOL-Original apresentaram acréscimo acentuado com o aumento da temperatura. $\mathrm{O}$ mesmo não acontece com os biodieseis metílicos e etílicos de babaçu, os quais as composições diferem consideravelmente dos outros biodieseis estudados, por apresentarem uma concentração de metil laurato. Os outros dois modelos não mostraram essa dependência com relação à temperatura.

\section{CONCLUSÃO}

Dados de densidade para biodieseis metílicos e etílicos de soja, babaçu, milho e algodão foram determinadas para diferentes temperaturas. Os modelos GCVOL-Original, GCVOLBio e GCVOL-OL-60 foram utilizados para estimar densidades dos biodieseis. O modelo GCVOL-Bio apresentou o menor ARD para biodieseis metílicos e o modelo GCVOL-OL-60 para biodieseis etílicos. No entanto, os modelos analisados podem ser considerados representativos, pois os desvios médios relativos apresentaram valores inferiores a $1 \%$.

\section{REFERÊNCIAS BIBLIOGRÁFICAS}

ELBRO, H. S.; FREDENSLUND, A.; RASMUSSEN, P. Group Contribution Method for the Prediction of Liquid Densities as a Function of Temperature for Solvents, Oligomers, and Polymers. Ind. Eng. Chem. Res. 1991, 30, 2576-2582.

IHMELS, E. C.; GMEHLING, J. Extension and Revision of the Group Contribution Method GCVOL for the Prediction of Pure Compound Liquid Densities. Ind. Eng. Chem. Res. v. 42, p. 408-412, 2003.

KNOTHE, G.; VAN GERPEN, J. H.; Manual do Biodiesel. 2. ed., AOCS Publicações, Urbana, 2008.

PRATAS, M. J.; FREITAS, S.; OLIVEIRA, M. B.; MONTEIRO, S. C.; LIMA, A. S.; COUTINHO, J. A.P. Densities and Viscosities of Minority Fatty Acid Methyl and Ethyl Esters Present in Biodiesel. J. Chem. Eng. Data. v. 56, p. 2175-2180, 2011.

WALLEK, T.; RAREY,J. METZGER, J. O.; GMEHLING, J. Estimation of Pure-Component Properties of Biodiesel-Related Components: Fatty Acid Methyl Esters, Fatty Acids, and Triglycerides. Ind. Eng. Chem. Res. v. 52, p. 16966-16978, 2013. 